\title{
Study of Disorders of the Respiratory Systems Under the Influence of Atmospheric Emissions of the Metallurgical Complex
}

\author{
${ }^{1}$ Nina N. Zabolotskaya, ${ }^{2}$ Ramil T. Nasibullin \\ ${ }^{1,2}$ Kazan Federal University \\ Email: nasibullin.ramil@mail.ru
}

Received: 20 ${ }^{\text {th }}$ August 2019, Accepted: 30 ${ }^{\text {th }}$ September 2019, Published: $31^{\text {st }}$ October 2019

\begin{abstract}
Environmental problems are becoming more acute for modern humanity with every passing year. The quality of atmospheric air is of particular concern. It is polluted by the industrial emissions, car exhaust, energy enterprises and other anthropogenic sources [1]. Atmospheric air is a vital component of the natural environment, an integral part of the environment of human, plants and animals [2]. The environment is one of the significant factors, affecting the body of children, which is in the process of growth and development, and is more susceptible to the influence of various environmental factors [3]. It was revealed, that in the structure of the incidence of child population, the respiratory diseases were the first [10]. The task of the work was to study the features of the course of acute respiratory diseases (ARD) in young children, living in a large industrial center; and in parallel, to conduct a full-scale experiment on growing laboratory rats, which were in similar conditions of atmospheric air pollution from the emissions of metallurgical complex. Since the rat is a model, close to human in terms of response to external influences, it was supposed to study the morphological prerequisites for the course of acute respiratory infections in children. The presence of the pronounced structural changes of mucous membranes, trachea and bronchi in animals, located in the zone of maximum atmospheric pollution, was confirmed experimentally.
\end{abstract}

\section{Keywords}

Atmospheric Emissions, Metallurgical Complex, Respiratory System, Morbidity, Laboratory Rats, Morphological Precondition, Phenol.

\section{Introduction}

There is an increase in the incidence of diseases of respiratory system, sensory organs, and various allergic diseases, in the areas of the greatest air pollution, located near the large industrial enterprises. The main emissions from metallurgical plants are the following: dust, carbon monoxide, hydrogen sulfide, a number of hydrocarbons, including phenol, as well as other harmful substances. $[4,13]$ The state of the atmosphere affects the incidence rates even in different areas of industrial cities [5, 12].

Predisposition to bronchial asthma, bronchitis, conjunctivitis, pharyngitis, tonsillitis, chronic otitis is $40-60 \%$ higher in the areas with high levels of air pollution. Statistical analysis allowed to establish a relationship between the level of air pollution and such diseases as upper respiratory tract diseases, bronchitis, asthma, pneumonia, emphysema [6, 14]. The task of the work was to study the features of the course of acute respiratory diseases (ARD) in young children, living in a large industrial center, and in parallel, to conduct a full-scale experiment on growing laboratory rats, which were in similar conditions of atmospheric air pollution from the emissions of metallurgical complex. To solve the set tasks, it was necessary to characterize the living environment of sick children; to give clinical and laboratory analysis of the course of acute respiratory diseases in young children; and also to determine the morphological changes in the respiratory tract and organs of immunogenesis in growing young rats, arising under the influence of atmospheric pollution of the metallurgical complex, in experimental conditions.

\section{Methods}

The samples of atmospheric air, presented by the city's sanitary-epidemiological service were analyzed. Case histories of 155 young children with acute respiratory diseases were studied. A full-scale experiment was conducted on growing laboratory rats. Clinical and laboratory research were performed in two groups of children: the main group ( 85 children) lived within a radius of $1000 \mathrm{~m}$ from the metallurgical complex, the control group (70 children) - at a distance of 20,000 $\mathrm{m}$ from the source of air pollution. The impact of atmospheric emissions on growing laboratory rats was studied in a full-scale experiment. The experimental animals were placed in specially equipped chambers, placed in the areas, where the examined children lived. The first group of animals (25 individuals) was located within a radius of $1000 \mathrm{~m}$, and the second group (25 individuals) - over a distance of $20,000 \mathrm{~m}$ from the industrial complex. For the validity of results, newborn male rats were selected in the experiment, that allowed to evaluate the reactions of a growing organism. It is known, that a rat becomes sexually mature at 4 months. Upon reaching four months of age, some animals were euthanized. The histological studies of their respiratory organs (mucous membrane of trachea and bronchi) and spleen structures were performed. The remaining animals were euthanized after the recovery period - 1 month. It was also performed the histological studies of the above internal organs. 


\section{Results and Discussion}

The most typical atmospheric emissions of metallurgical enterprises are the following: aromatic hydrocarbons, gaseous sulfur compounds, carbon dioxide and carbon monoxide, nitrogen oxides, ammonia, and dust with complex chemical composition [11]. The content of a complex of volatile toxic substances in the air, such as phenol, hydrogen sulfide, ammonia, carbon monoxide, which easily enter the body through the respiratory tract, is of the greatest importance [9]. The analysis of atmospheric air samples showed, that in the area where the main group of children lived, the average phenol content exceeded MPC by 14.2 times, hydrogen sulfide - by 16.8 times, dust - by 1.89 times, and the ammonia content was within the limits of the permissible norms. Assessing the degree of air pollution in this area, using the complex indicator (P) [8], it is necessary to note its strong pollution (IV degree), $\mathrm{P}$ is 20.5. In the area of residence of the control group, the phenol content exceeds MPC by 1.7 times, hydrogen sulfide - by 1.5 times, the content of other ingredients is satisfactorily. The value of the complex indicator of atmospheric air pollution $(\mathrm{P})$ in this area is 1.85 , that indicates the acceptable level of harmful substances in the air. So, this area can be considered as conditionally clean. All other factors, such as tap water, living conditions, food, and intension of transport in the district are the same. The method of selective extract of data from primary medical documentation (2966 case histories) on appealability was used, in order to study the prevalence and structure of bronchopulmonary diseases in children. As the data showed, the pathology of respiratory tract was dominant in the structure of diseases of the observed contingent of children, which amounted to $64.4 \%$ (Table 1 ).

\begin{tabular}{|c|c|c|}
\hline Nosological forms & Morbidity level (per 1000 children) & Disease structure, $\%$ \\
\hline Acute respiratory infections & 810.4 & 58.8 \\
\hline Acute bronchitis & 42.4 & 3.5 \\
\hline Acute pneumonia & 28.4 & 2.1 \\
\hline Total bronchopulmonary diseases & 881.2 & 64.4 \\
\hline Total morbidity & 1591.3 & 100 \\
\hline
\end{tabular}

Table 1: Prevalence and Structure of Bronchopulmonary Diseases among Children of a Large Industrial Center

Due to the different living conditions of the main and control groups of the observed children, the prevalence and structure of bronchopulmonary diseases were studied in two areas: at a distance of $1000 \mathrm{~m}$ (the $1 \mathrm{st}$ zone) and $20,000 \mathrm{~m}$ (the 2nd zone) from the metallurgical complex (Table 2).

The analysis of the data indicates that in the 1st zone, located in close proximity to the industrial complex, the incidence rate exceeds the citywide indicators by 1.4 times, and the indicators of the 2 nd zone - by 1.7 times. Young children, living near the metallurgical center, more often had acute respiratory infections, acute bronchitis and, especially, acute pneumonia, during the year. These circumstances prompted the study of the causes of development of more frequent and severe dysfunctions of respiratory system in young children with acute respiratory infections. When assessing the severity of disease, it was found that the complicated forms of acute respiratory infections in the main group were detected in $64.7 \%$ of children (55 patients), while in the control group - in 51.4\% (36 children).

\begin{tabular}{|c|c|c|c|c|c|c|}
\hline \multirow{2}{*}{$\begin{array}{c}\text { Area of } \\
\text { residence }\end{array}$} & Indicators & Total morbidity & $\begin{array}{c}\text { Acute } \\
\text { respiratory } \\
\text { infections }\end{array}$ & $\begin{array}{c}\text { Acute } \\
\text { bronchitis }\end{array}$ & $\begin{array}{c}\text { Acute } \\
\text { pneumonia }\end{array}$ & $\begin{array}{c}\text { Total } \\
\text { bronchopulmonary } \\
\text { diseases }\end{array}$ \\
\hline \multirow{2}{*}{ zone 1 } & Morbidity level & 2070.7 & 1174.1 & 21.5 & 22.5 & 1218.1 \\
\cline { 2 - 7 } & Structure, \% & 100.0 & 56.7 & 2.1 & 2.2 & 61.0 \\
\hline \multirow{2}{*}{ zone 2 } & Morbidity level & 1286.3 & 697.2 & 13.2 & 16.0 & 726.4 \\
\cline { 2 - 7 } & Structure, \% & 100.0 & 54.2 & 2.8 & 1.1 & 58.1 \\
\hline
\end{tabular}

Table 2: Prevalence and Structure of Bronchopulmonary Diseases among Children of the Studied Areas

The analysis of the structure of complications of acute respiratory diseases showed that in the main group, respiratory tract complications were observed more often by 1.4 times, than in the control group (Fig. 1). Moreover, among 3-yearold children of the main group, bronchopulmonary complications were identified more often by 1.7 times, than in children of the same age in the control group.

The main clinical symptoms of acute respiratory infections in the examined children are presented in table 3 . It can be seen, that the intoxication, prolonged duration of fever, pronounced catarrhal phenomena in the form of increased mucus secretion by glands of the respiratory tract, moist rale, symptoms of respiratory failure were observed more often in the dynamics of development of pathological process in children of the main group, living in the zone of maximum effect of atmospheric emissions. 


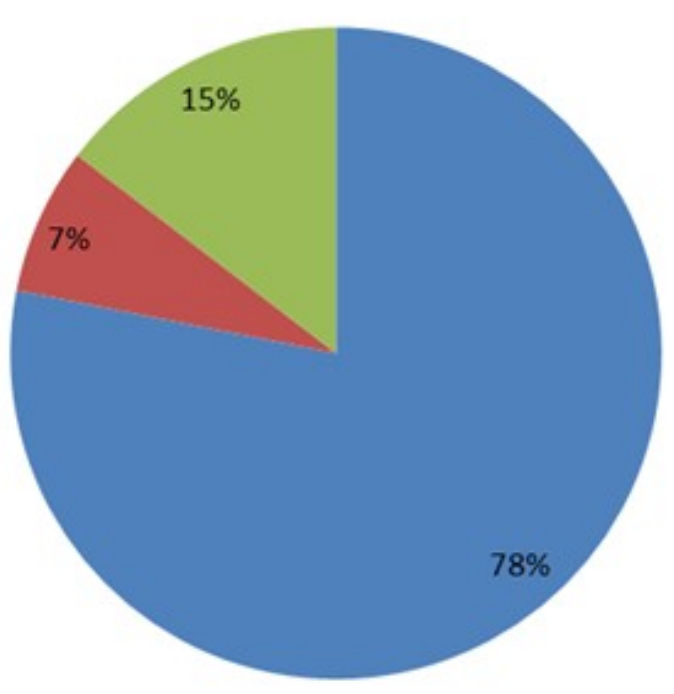

$=1 \quad=2 \quad 13$

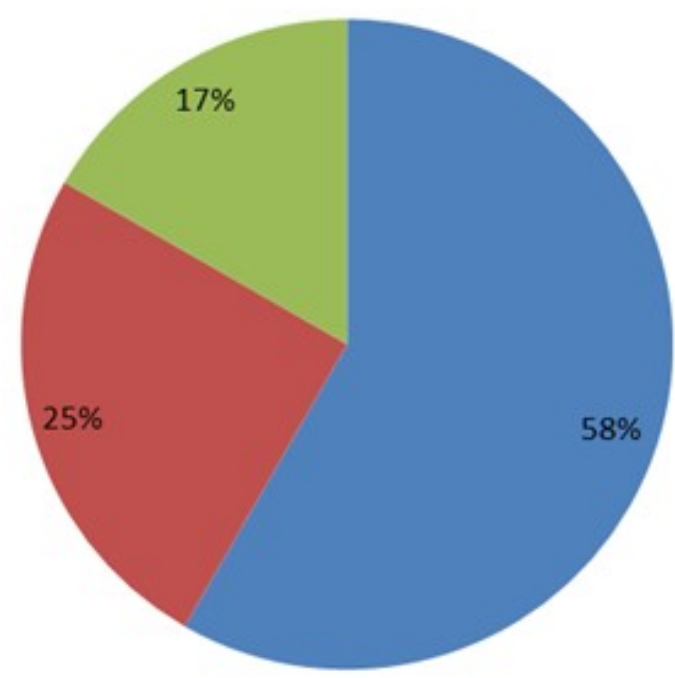

$=1 \quad 2 \quad=3$

b)$$
\text { ) }
$$

a)

Figure 1: Analysis of the Structure of Complications a: Main Group of Children; b: Control Group of Children; 1: Bronchopulmonary Complications; 2: Otits; 3: Other Complications.

\begin{tabular}{|c|c|c|c|}
\hline \multirow{2}{*}{ № } & Symptoms & \multicolumn{2}{|c|}{ Severity of symptoms in \% } \\
\cline { 3 - 4 } & & $\begin{array}{c}\text { Main group of } \\
\text { children }\end{array}$ & $\begin{array}{c}\text { Control group of } \\
\text { children }\end{array}$ \\
\hline 1. & Intoxication & 47.3 & 25.0 \\
\hline 2. & Fever duration more than 7 days & 50.9 & 47.3 \\
\hline 3. & Catarrhal phenomena of the respiratory system & 67.3 & 30.6 \\
\hline 4. & Duration of catarrhal period over 8 days & 87.3 & 50.0 \\
\hline 5. & Increased secretory activity of the glands of the respiratory tract & 67.3 & 22.2 \\
\hline 6. & Duration of hospital stay more than 30 days & 12.7 & 5.5 \\
\hline
\end{tabular}

Table 3: Comparative Characteristics of the Main Clinical Manifestations of ARI in the Studied Group of Sick Children

The investigations were conducted in parallel in both groups, at the same periods of the year, and the etiological factors did not differ significantly. Adenoviruses (28.2\% and $31.2 \%$ in the main and control groups, respectively) and parainfluenza viruses $(33.0 \%$ and $31.5 \%$, respectively) were predominantly identified in both groups. Moreover, adenoviruses were detected more often in cases of the complicated course of disease $(18.2 \%$ and $19.4 \%$ in the main and control groups, respectively). For the objective assessment of laboratory and immunobiochemical studies, similar parameters were studied in 25 apparently healthy children.

Clinical and biochemical laboratory studies, conducted in the initial phase of disease, revealed a tendency to the development of early leukocytosis, accelerated ESR, dysglobulinemia, in the group of children, living in the zone of the greatest influence of atmospheric pollution of metallurgical complex. Well-pronounced dysgammaglobulinemia in children of the main group $(\mathrm{P}<0.001)$ indicates the decrease in the body defenses, and derangement of the immunobiological processes, associated with the production of antibodies and impaired humoral immunity. The indicators of humoral immunity were evaluated by the activity of B-lymphocytes system. The researches showed that immunoglobulins of classes $\mathrm{A}$ and $\mathrm{M}$ underwent the greatest change. At the same time, in children of the main group, both in complicated and uncomplicated forms, immunoglobulins A had a pronounced tendency to decrease $(\mathrm{P}<0.001)$, and the concentration of immunoglobulins $\mathrm{M}$ significantly increased $(\mathrm{P}<0.001)$. Revealed dysfunction of $\mathrm{B}$-component of immune system is confirmed by severe hypogammaglobulinemia $(\mathrm{P}<0.05)$. Taking into account that an isolated study of humoral immunity without determination of the cellular component does not give the full picture of the ratio of body's defenses, the quantitative and functional assessments of cellular immunity were carried out. As a result, the inhibition of T-cellular immunity was revealed, more pronounced in children, living near the industrial complex. 
The experiment was conducted on growing white rats, placed in chambers, and located in the areas of residence of the examined children: the first group of animals (25 individuals) within a radius of $1000 \mathrm{~m}$, and the second group (25 individuals) at a distance of $20,000 \mathrm{~m}$ from the industrial complex. It was supposed to study the local damaging effect of atmospheric emissions of the industrial complex on the mucous membrane of the respiratory tract, and the general toxic effect on the immune system, as two main mechanisms, determining the features of the course of acute respiratory infections. Histological studies found that the changes in the type of irritation in the form of hyperplasia of tracheal glands with the areas of atrophy of tracheal mucous membrane (Fig. 2) prevailed in the organs of rats of the first group. In animals of the second group, the changes were defined as minor hyperplasia of tracheal glands (Fig. 3).

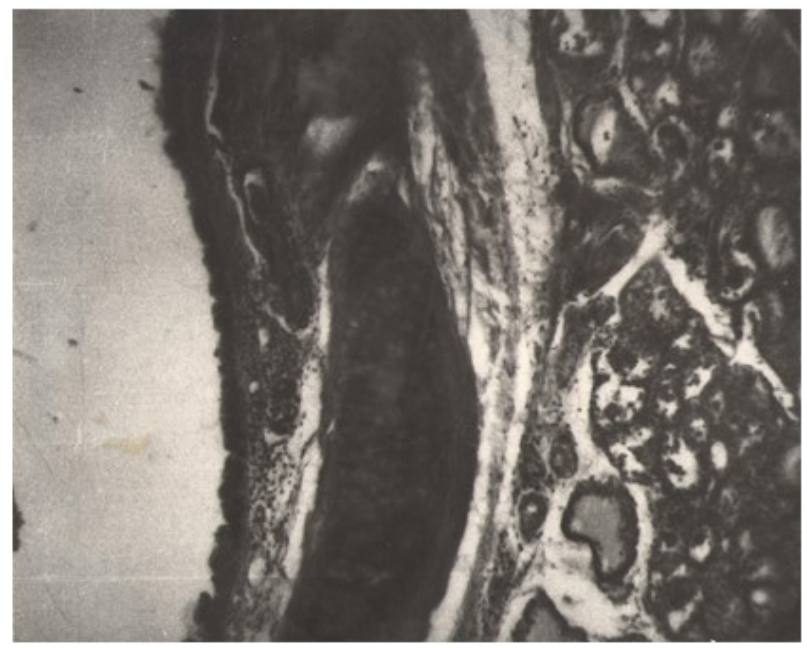

Figure 2: Hyperplasia of Glands and Atrophy of Mucous Membranes of Trachea

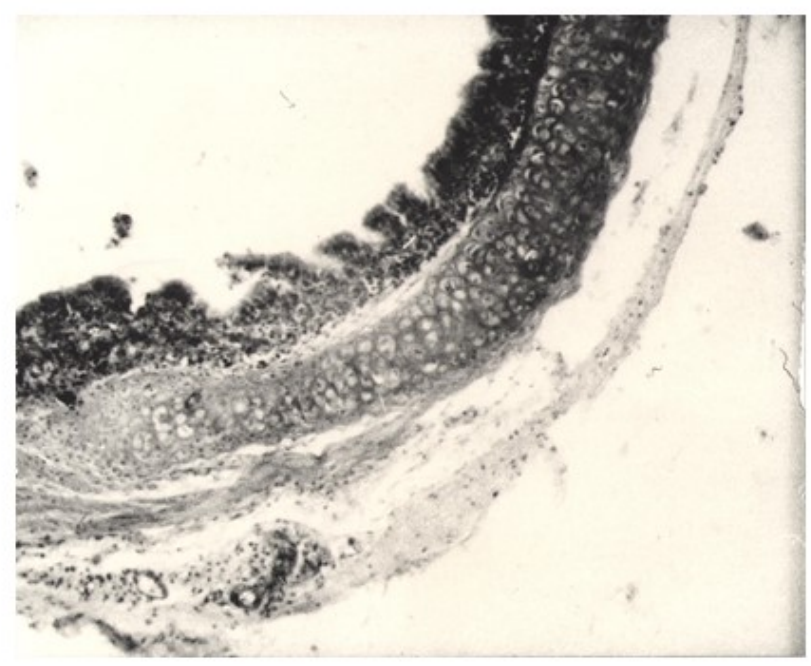

Figure 3: Medium Hyperplasia of Tracheal Glands

In the first group of animals, focal infiltration of the bronchial mucosa was found (Fig. 4); while in the second group of animals there were no changes in the structures of bronchi, during the entire period of observation (Fig. 5). 

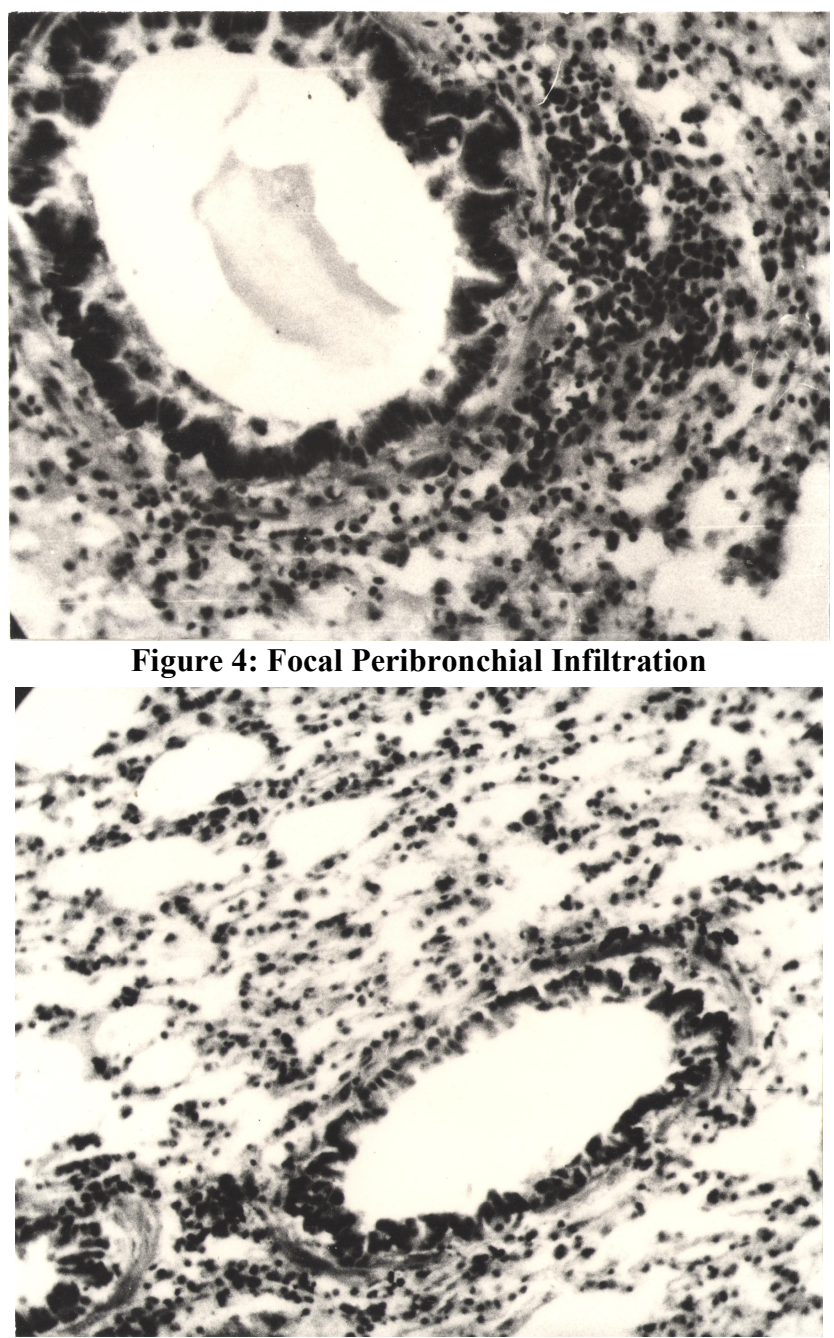

Figure 5: Physiological (Normal) Structure of Bronchus

With regard to the changes in the immune system, in particular, in the spleen of animals of the first group, hyperplasia of lymphoid structures was noted with an increase in the growth centers of lymphoid follicles (Fig. 6); while in young rats of the second group, slight hyperplasia of lymphoid follicles of spleen was revealed (Fig. 7).

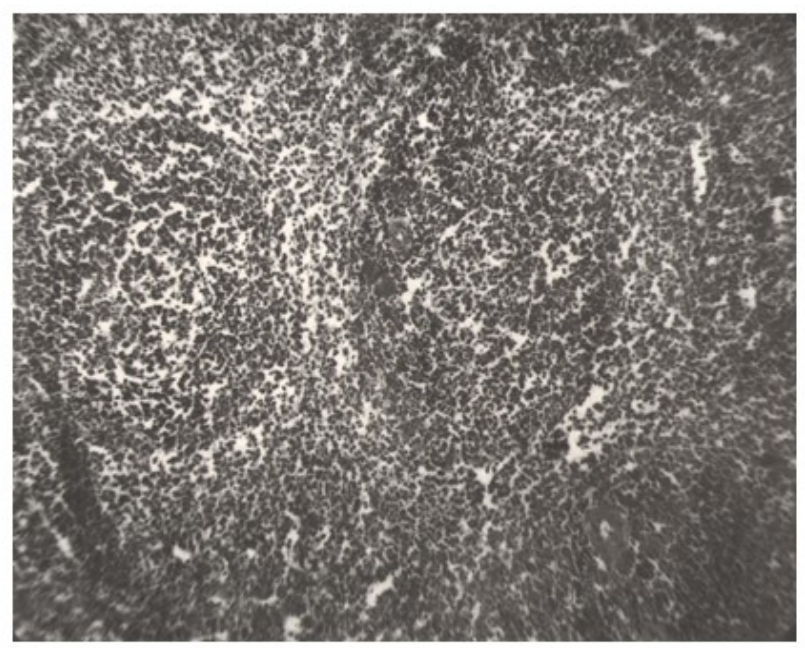

Figure 6: Hyperplasia of Spleen Follicles 


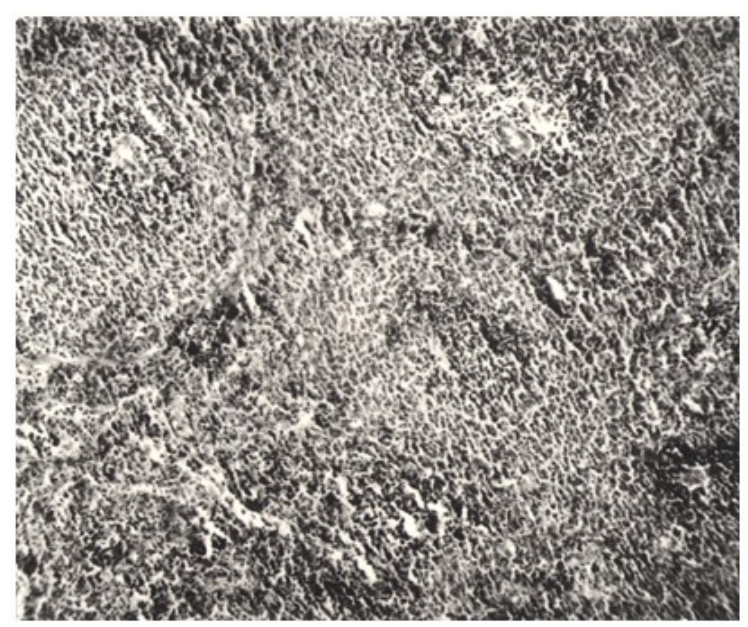

Figure 7: Hyperplasia of Lymphoid Follicles of Spleen

At the same time, the activity of restoration of the affected structures was inversely related to the degree of air pollution. In the animals of the first group, the structural disorders remained after the recovery period: cellular infiltration and sclerosis of the mucous membrane of trachea, focal cellular infiltration of bronchi (Fig. 8) and the processes of atrophy of the lymphoid tissue of spleen (Fig. 9).

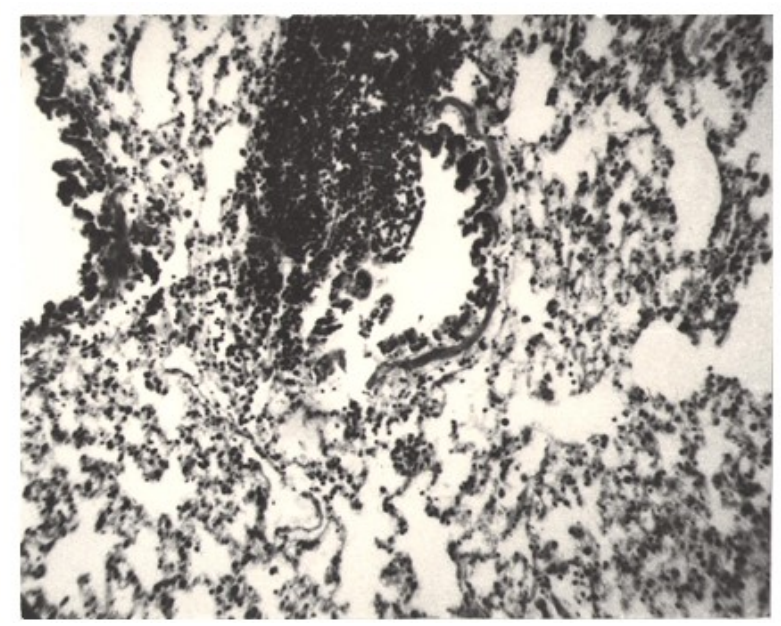

Figure 8: Cellular Infiltration

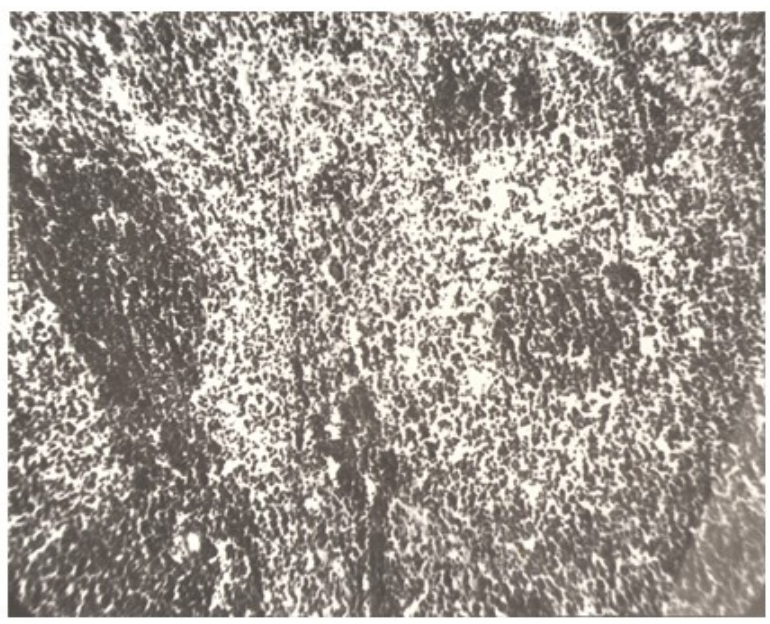

Figure 9: Atrophy of Lymphoid Follicles of Spleen 


\section{Summary}

In the structure of diseases of the investigated contingent of children, the pathology of respiratory tract was dominant, and amounted to $64.4 \%$. In the 1 st zone, located in close proximity to the industrial complex, the incidence rate was 1.4 times higher than the citywide indicators, and 1.7 times higher than the indicators of the 2nd zone. Young children, living in a short distance from the metallurgical center, had acute respiratory infections, acute bronchitis and, especially, acute pneumonia more often, during the year. The analysis of the structure of complications of acute respiratory diseases showed, that in the main group, respiratory tract complications were observed more often by 1.6 times, than in the control group. Moreover, among 3-year-old children of the main group, bronchopulmonary complications were identified more often by 1.7 times, than in children of the same age in the control group. This circumstance confirms the assumption that the longer children live under the influence of emissions from the metallurgical complex, the greater is the risk of formation of conditions for the development of complicated protracted course of acute respiratory infections. The features and severity of the main symptoms of disease allow to suggest the longer decompensation of the bronchopulmonary system in cases of acute respiratory infections in patients of this group. Immunobiochemical studies, carried out among the sick children of the main group, revealed the derangements of B-and T-components of immune system. Therefore, the patients of the main group are prone to the development of protracted complicated forms of ARI, due to the lability of nocifensors, manifested by the early deficiency of T-component of immune system, against the background of dysfunction of B-system, dysglobulinemia with a decrease in gamma globulins, and an increase in the content of alpha2-globulin fraction, indicating significant destructive and inflammatory reactions of the child's body. Explanations and confirmations of the reliability of obtained clinical and laboratory data were received in the experiment on growing white rats.

In a full-scale experiment, it was proved that the adaptive capabilities of animals of the first group, living in close proximity to the industrial enterprise, were significantly reduced. This was confirmed by histological studies: the presence of pronounced irreversible changes in the organs of immunogenesis, in the mucous membranes of trachea and bronchi. At the same time, the number of irreversible destructive disorders in the respiratory and immunogenesis organs increased, as the rats were approached to the industrial complex. Therefore, the obtained data indicate a significant severity of morphological changes in the mucous membrane of the respiratory tract and organs of immunogenesis, in animals of the first group. This can lead to the development of more severe processes, prone to a protracted, complicated course of desease. The revealed histological changes in the organs of animals confirmed the features of clinical and laboratory changes in children, living in the immediate vicinity of the industrial complex, indicating the lack of local protective factors, and the low level of adaptive capabilities of the child's body.

\section{Conclusions}

Thus, the high anthropogenic load of atmospheric emissions of the metallurgical complex on the human environment leads to the significant deteriorations of health of population and, above all, of children. The studies and comparisons of clinical, laboratory and morphological parallels made it possible to determine the prerequisites for the formation of respiratory and immune disorders in young children, living in close proximity to the industrial center.

\section{Acknowledgements}

The work is performed according to the Russian Government Program of Competitive Growth of Kazan Federal University.

\section{References}

[1] The Causes of Air Pollution in Large Cities of the World [Electronic resource] - Access mode: https:/galoportal.ru/poleznoe/novosti/zagryazneniye-vozdukha-v-gorodah/\#ixzz5ahYAZa00.

[2] Federal Law "On Protection of Atmospheric Air" of May 04, 1999, No. 96-FZ.

[3] Lysenko A.I., Yarullin A.Kh., Dautov F.F. The State of Health of Preschool Children in the Territories with Different Levels of Anthropogenic Load // Hygiene and Sanitation. - 2002. - No. 4. - Pp. 41-13.

[4] Bratsuk A.A., Esimova A.T., Ignatovich I.A. The Analysis of Statistics of Harmful Emissions into the Atmospheric Air // Young Scientist. - 2017. - No. 50. -Pp. 129-130.

[5] Zabolotskaya N.N. Forecasting of the Outcomes and Prevention of Complications of Acute Respiratory Infections in Young Children, Living in the Mining and Metallurgical Industrial Center. Thesis for a Candidate Degree in Medical Sciences, 1987. - 166 p.

[6] Atmospheric Emissions and Air Pollution in the City [Electronic resource] - Access mode: http://ekrost.ru/poster/vliyanie-atmosfernyh-vybrosov-na-ekologicheskuyu-situaciyu-goroda.html.

[7] Pinigin M.A. Evaluation of the Combined Effect of Atmospheric Pollution by the Selection of its Coefficients // Hygiene and Sanitation. - 1985. - No.9. - Pp. 74-76.

[8] Kagawa J. Health Effects of Air Pollutants and their Management// Atmospheric Environment. - 1984. - No. 3. - V. 18. - Pp. 613 - 620. 
[9] Mikhailova E.V. The State of Health of Children in Conditions of Air Pollution // Hygiene and Sanitation. - 2005. No. 2. - Pp. 49-51.

[10] Suchkov V.V. The Impact of Air Pollution on the Formation of Health Risks for the Population, Living in the Industrial Centers // Modern Medicine: Urgent Issues: Collection of Articles on the Materials of the XIX International Scientific and Practical Conference. - Novosibirsk: SibAK, 2013, Pp. 52-59.

[11] Toxic Substances and Disease Registry U.S.DEPARTMENT OF HEALTH AND HUMAN SERVICES Public Health Service. Agency for [Electronic resource] - Access mode: http:/www.atsdr.cdc.gov/toxprofiles.

[12] Smurov A.V., Snakin V.V., Komarova N.G. The Current State of Atmospheric Air // Ecology of Russia, Textbook, 2012, p. 12-33.

[13] Bennet B.G. Exposure of Man to Environmental selenium-an Exposure commitment Assessment// Sci of Total Environ. - 1983. - №2. - Pp.117 - 127. 